\title{
Negotiating skills
}

The Collins English Dictionary defines negotiation as "a discussion set up or intended to produce a settlement or agreement". It is a skill everyone uses on a regular basis in daily life, often without realising. A plan to meet friends for an evening meal for example involves agreeing a time and venue-this is negotiation. As it is the process of coming to terms with the "other side" and trying to get the best deal possible it is necessary to accept the fact that a conflict of interest does exist. There is an atmosphere of uncertainty until the deal is completed and one side may gain and one may lose relative to their opening position. For this skill to be successfully applied when working with clinical management colleagues, a formal set of guidelines is necessary. In this article I highlight some of the problems which can arise and offer a systematic approach to this difficult but rewarding management activity.

\section{Negotiation strategy}

There are four stages to negotiation: (1) preparation; (2) opening; (3) bargaining; (4) closing.

\section{PREPARATION}

This is probably the most important aspect of successful negotiation. It may only take a few minutes to complete or, at the other extreme in complex negotiations (for example, trade unions negotiating pay rises at ACAS) can take days or weeks.

\section{(a) Set objectives}

What is your ideal target?

What is your minimum target?

What is your compromise position? Assemble data and evidence to support your case.

\section{(b) Decide on a strategy}

This is important in complex issues. Who will comprise your team? How will you present your data? Who else will you lobby? When and where will you meet and how many times will you need to meet? This latter depends on how successful negotiation is.

OPENING

This is the stage when both sides meet and initial bargaining positions are revealed.

(a) Open realistically and be non-committal.

(b) Challenge opponents' position but do not fence them in and hence limit their flexibility.

(c) Reassess your own position, strengths, and weaknesses after hearing from the other side.

\section{Committees - a personal view}

The NHS is run by committees. Clinical, academic, and educational work, manpower and appointment decisions, as well as much routine management and administrative work is ultimately controlled by a committee. Inevitably all consultants become involved in this work at some stage in their careers. $A \& E$, because of the small numbers of (d) Be prepared to move position without making any major concessions.

BARGAINING

This is the nitty-gritty stage when movement towards a deal is made. In complex cases (such as ACAS) it can be protracted and difficult, particularly if both sides have entrenched rigid positions.

(a) Probe opponents weaknesses and try to convince them to abandon their position.

(b) Check if your own position holds good in view of bargaining and consider whether to exert pressure or make concessions.

(c) Make conditional proposals. Never let them be one sided and always bargain on the whole package. Do not allow items to be picked off one by one as this weakens your overall position.

CLOSING

This is time to fine tune matters leading to completion of discussions and (metaphorically at least) the shaking of hands. Will they stick to their position or move? Make your final moves and trade offs and summarise what has taken place, highlighting the degree of concession or movement. As you move to close a deal, apply pressure if necessary through the threat of consequences if a deal is not reached. If you cannot reach a deal be prepared to give your opponent two choices only, which should be known or anticipated from your "preparation stage".

Do not make any final offers unless they are meant (or your bluff will be called). Do not hurry if it will compromise you, keep cool, and if necessary plan to meet again. If you do meet again follow the same basic formula as above.

\section{Summary}

The detailed framework discussed in this article is not needed in every case as the majority of situations requiring negotiation will be settled rapidly and harmoniously. In more difficult and complex cases the key to successful negotiation lies in good preparation. Although you should have an ideal end point to aim for and good data to back up your case, always prepare a fall back position beyond which you will not move and stick to it. Remember your overall strategy and stay cool throughout. Good luck!

GEOFFREY HUGHES

Accident and Emergency Department, Bristol Royal Infirmary, Bristol BS2 $8 \mathrm{HW}$

consultants, will be more involved with committees than colleagues in larger specialties where the responsibility (or burden) is more readily diluted.

Committees vary considerably in their importance and the interest they offer to the constituent members, both these variables changing throughout the year. They make crucial and far 
reaching decisions, often after heated debate, but more commonly "rubber stamp" routine matters with minimal debate or "on the nod".

You will become a member of a committee by one of four basic routes.

(1) Personal invitation-This implies that you have a special attribute that the committee needs. It may be specialist knowledge or experience or personal enthusiasm and energy or a combination of these. If you accept attendance is mandatory. It could be a short or a long term commitment and occasionally will be just a "one off".

(2) Secondary to professional post - This type of work comes with the job or even as a result of "muggin's turn". These posts often have a defined period and include faculty or university representation on appointments committees, specialty representation in educational or academic work, or management and finance meetings as a clinical director. Attendance at these is important and if you personally cannot attend try to send a representative.

(3) By election-Election to a post can be closed or open. It may be to hold a specific office for a defined period (treasurer or secretary, etc) or to represent a body of colleagues and voice their joint opinion.

(4) Automatic membership - Simply by being a consultant one will have automatic entry to certain committees. This may include the hospital medical committee, specialty divisions, and regional professional groups. Attendance will be variable and is non-essential.

\section{Committee etiquette}

If you are invited to join a committee ignore the flattery to your ego and ask yourself the following questions before you accept:

(1) Do you want to do it?

(2) Have you got the time to do it?

(3) Are you interested in the main activities of the committee and will you be able to maintain your interest? (4) Does the committee have an executive role or a routine rubber stamping role or even a "gate keeping" role? Information on this will affect your attitude to it.

If you do not think you can offer a satisfactory contribution, decline politely, explaining why. If you are pressed or have to accept by virtue of your position then accept gracefully and make the best contribution that you can.

It is an old but partially true cliché that decisions made by committee are frequently agreed in the corridors before it actually meets. What the cliché indicates is the importance of planning and preparation to enable committees to work successfully and smoothly. The following are some useful tips:

(1) Speak to the chairman informally or write to him formally to place items on the agenda. If you attempt to bring issues up without warning under the item "any other business", people can be caught on the hop and a first response will often be negative.

(2) Be prepared to lobby other members about a particular item if necessary. This is legal and above board. It will help smooth things through "on the nod" or with minimal debate. Some items will be so "hot" that genuine and passionate debate with voting will actually take place in the meeting and prior lobbying will be of no help.

(3) You should receive an agenda well in advance of the next meeting. Study it carefully and see what other items are being generated.

(4) If you cannot go to the meeting send apologies to the chairman. These apologies will be minuted.

(5) If you are to speak to an agendered item liaise with the chairman beforehand to discuss time limits and tactics, etc. (6) At the meeting keep your mouth shut unless you have something to say. Don't waste words with waffle and do not waste time. When your specific item arises await the chairman's permission to speak. Be prepared, be concise, and anticipate questions and objections. Handouts and briefing papers for distribution are occasionally helpful. Let the chairman control the debate. Remain cool.

(7) You should receive minutes within a few days or a week or two after the meeting has finished. Check them carefully. If you disagree with the minutes you can write to the chairman or secretary or bring your disagreement up at the next meeting. All minutes should be presented at the following meeting for confirmation of accuracy.

Recognise that standing on a committee can vary from being a privilege to a routine part of your work to a chore. If you repeatedly find them "mind numbingly dull" then you need to consider your position on it. Make better use of your time by resigning and thus opening up your place to someone with more interest and energy. They will be of greater benefit to the committee than somebody who is bored. Remember that no one is indispensable.

Finally, try and ensure your committee is not one that would be designed by a camel nor one that would design a camel. Try not to hold meetings purely for the sake of it. Strive hard to keep the committee active, relevant, and concise.

GEOFFREY HUGHES Marlborough St, Bristol, Avon BS2 $8 \mathrm{HW}$ 